\title{
PENGARUH LATIHAN KECEPATAN DAN KELINCAHAN TERHADAP LEMPAR TANGKAP BOLA KASTI UNTUK SISWA- SISWI KELAS IV SEKOLAH DASAR NEGERI 19 KOTA BENGKULU
}

\author{
Febrian Rizyanto \\ Universitas Bengkulu \\ frizyanto@gmail.com \\ Syafrial \\ Universitas Bengkulu \\ Yarmani \\ Universitas Bengkulu
}

\begin{abstract}
Abstrak
Penelitian ini bertujuan untuk mengetahui apakah latihan kecepatan dan kelincahan memberikan perngaruh yang signifikan terhadap peningkatan kemampuan lempar tangkap dalam permainan bola kasti. Metode yang digunakan dalam penelitian ini adalah metode eksperimen, dengan variabel bebas adalah kecepatan dan kelincahan, dan variabel terikatnya adalah teknik lempar tangkap bola kasti. Sampel yan di gunakan dalam penelitian ini sebanya 40 orang siswa - siswi sekolah dasar negeri 19 dan sebagai pembanding siswa - siswi sekoah dasar negeri kota bengkulu. Instrument atau alat pengumpulan data yang di gunakan dalam penelitian ini adalah lari sprint 30 meter, lari bolak balik dengan jarak 10 meter dengan 4 kali bolak - balik dan lempar tangkap ke dinding target 2 meter dengan waktu 30 detik. Berdasarkan pengolaan dan analisis data yang di peroleh, maka hasil penelitian ini adalah rata - rata tes awal sebesar kecepatan 42,65. kelincahan 19,66 dan lempar tangkap 59,60 rata - rata tes akhirnya kecepatan 56,14. Kelincahan 5,06 dan lempar tangkap 7,20 rata - rata beda sebesar 1,9. Kesimpulan dari penelitian ini, dilihat dari data maka latihan kecepatan dan kelincahan memberikan pengaruh yang signifikan terhadap lempar tangkap bola kasti.
\end{abstract}

Kata kunci : latihan kecepatan dan kelincahan.

\section{Abstract}

This study aims to determine whether speed and agility exercises have a significant effect on improving catching abilities in roundball games. The method used in this study is the experimental method, with the independent variables being speed and agility, and the dependent variable is the round ball catching technique. The sample used in this study was 40 students - 19 public elementary school students and as a comparison for students at the base of the city of Bengkulu. The data collection instrument or tool used in this study is a 30-meter sprint, running back and forth with a distance of 10 meters with 4 times back and forth and throwing a catch into the target wall of 2 meters in 30 seconds. Based on the management and analysis of the data obtained, the results of this study are the initial test average of 42.65 . agility 19.66 and catching 59.60 the average test finally speeds 56.14. Agility 5.06 and throw catch 7.20 - the average difference of 1.9. The conclusion of this study, judging from the data, is that speed and agility training have a significant effect on round ball catching.

Keywords: exercise speed and agility 


\section{PENDAHULUAN}

Berdasarkan pengamatan peneliti selama ini Pada dasarnya siswa/i Sekolah Dasar Negeri 19 kota Bengkulu adalah siswa yang aktif dalam mata pelajaran umum, terutama pada mata pelajaran PJOK (Pendidikan Jasmani, Olahraga dan Kesehatan), umumnya dalam keaktifan tersebut siswa dapat melakukan pukulan, tangkapan, lemparan dan berlari dengan benar, akan tetapi menurut hasil studi pendahuluan yang peneliti lakukan pada tanggal 31 Januari 2017 terhadap Guru dan Murid yang bersangkutan bahwa peneliti telah menemukan masalah yang dihadapi oleh siswa-siswi kelas IV Sekolah Dasar Negeri 19 kota Bengkulu yaitu kecepatan dan kelincahan berlari pada lempar tangkap bola kasti kurang dipelajari. Sehingga dalam permainan bola kasti tersebut kurang teknik dan peraturan yang di kuasai. Namun ada juga beberapa siswa yang mengetahui, dan mempelajari peraturan dan teknik berlari dalam permainan bola kasti tersebut.

Beberapa hal penting harus dilakukan oleh siswa adalah mempelajari kecepatan dan kelincahan dalam lempar tangkap bola kasti sehingga ketika memainkan permainan tersebut siswa tidak lagi diam dan bingung dengan apa yang dilakukan. Yang kemudian siswa menciptakan sifat kerja sama, sportivitas, dan jujur tak lupa pada sifat fairplay.

Untuk mengatasi permasalahn tersebut, yang mempengaruhi kecepatan dan kelincahan pada siswa/i akan dilakukan proses latihan lari sprint jarak 30 meter dengan waktu secepatnya dan lari bolak-balik dengan menggunakan jarak 10 meter dengan 4 kali bolak balik kemudian melakukan lempar tangkap sebanyak banyaknya selama 30 detik. Sehingga dapat meningkatkan kecepatan dan kelincahan dalam teknik lempar tangkap, kemudian akan dilakukan pre-test dan post-test pada siswa/i.

Menurut Giri wiarto (2015:47) "Kecepatan adalah kemampuan untuk menggerakkan tubuh dari satu tempat ke tempat lain dalam waktu secepat mungkin". Giri wiarto (2015:46) "kecepatan adalah sebagai kemampuan berdasarkan kelentukkan dalam satuan waktu tertentu. Dalam melakukan lari 4 detik, semakin jauh jarak yang ditempuh semakin tinggi kecepatan".

Giri wiarto (2015:47) "Kelincahan (Agiltas) adalah kemampuan untuk menggerakkan badan atau mengubah arah secepat mungkin". Giri wiarto (2015:46)" kelincahan adalah kemampuan seseorang mengubah arah dari posisi tubuh dengan cepat dan tepat pada waktu bergerak pada satu titik ke titik lain dalam melakukan lari zig-zag, semakin cepat waktu yang ditempuh maka semakin tinggi kelicahannya".

Berdasarkan latar belakang yang disampaikan diatas, peneliti tertarik untuk melakukan penelitian terhadap siswa dengan menggunakan prosedur penelitian pre-test dan post-test, menurut peneliti belum ada penelitian ilmiah yang dilakukan mahasiswa PJKR yang berjudul "Pengaruh Latihan Kecepatan Dan Kelincahan Terhadap lempar tangkap Bola Kasti Siswa/I Kelas Iv Sekolah Dasar Negeri 19 Kota Bengkulu".

Rumusan masalah dalam penelitian ini adalah: masalah yang dapat dirumuskan sebagai berikut "Apakah ada pengaruh latihan kecepatan dan kelincahan terhadap lempar tangkap bola kasti siswa-siswi kelas iv sekolah dasar negeri 19 kota bengkulu?". Tujuan kegiatan penelitian ini adalah: untuk mengetahui pengaruh latihan kecepatan dan kelincahan terhadap lempar tangkap bola kasti siswa-siswi kelas iv sekolah dasar negeri 19 kota bengkulu.

\section{Lapangan Kasti}

Manurut Ade Mardiana (2009:4.28) Lapangan permainan bola kasti berbentuk empat persegi panjang dengan ukuran luasnya adalah lebih $\pm 60 \mathrm{~m}$ dan lebar $30 \mathrm{~m}$ (tidak mutlak). Lima meter dari panjang lapangan dipergunakan untuk ruangan tempat penjaga belakang, tempat pemukul, 
tempat pelambung, dan tempat pemain pemukul. Lapangan dilengkapi dengan tiang penyelamat yang diletakkan jaraknya 5 meter dari garis pemukul dan 5 meter dari garis samping. Sedangkan tiang hinggap ada dua buah yang masing-masingnya diletakkan berjarak 10 meter dari tiang yang lainnya, 10 meter dari garis belakang dan juga 5 meter dari garis samping.

Bagian pangkal lapangan terdapat ruangan atau petak pemukul juga 5 kali 5 meter dari garis samping. Sedangkan tiang hinggap ada dua buah yang masing - masing diletakkan berjarak 10 meter dari tiang yang lainnya 10 meter dari garis belakang dan juga 5 meter dari garis samping. Hestty P. Utami (2008:5). "Sarana yang digunakan yaitu lapangan yang didalamnya terdapat 3 tiang dan dua kotak yang sudah di beri garis".

\section{Peraturan Permainan}

Menurut Hestty P. Utami (2008:5) Pemain berjumlah 12 orang akan tetapi Jumlah pemain tiap regu dapat disesuaikan dengan keadaan di sekolah. Tunjuk salah satu seorang untuk menjadi kapten regu. Menurut Sukrisno (2009:2) mengatakan bahwa peraturan dalam permainan bola kasti yaitu:

\section{Melempar Bola}

Lemparan bola datar, Lemparan bola melambung ke atas, Melambungkan bola pada si pemukul, Lemparan bola menggelinding

\section{Menangkap bola}

Sikap badan dan posisi tangan pada saat menangkap bola sangat tergantung pada datangnya bola dengan datar, parabol, atau menggelinding.

\section{Menangkap bola datar}

Bola yang datangnya mendatar dan tepat di depan dada, pada saat bola tertangkap jari-jari segera ditutup dan kedua tangan ditarik ke belakang, supaya bola tidak loncat lepas kembali (muntah).

\section{Menangkap bola rendah}

Cara menangkap bola rendah sama dengan menangkap bola yang datangnya mendatar, hanya saja kedua lutut harus ditekuk agar badan merendah. Penekukan lutut disesuaikan dengan datangnya bola.

\section{Menangkap bola parabol/melambung ke atas}

Sikap permulaan kaki kiri berada di depan, kedua tangan dijulurkan ke arah datang bola dengan posisi telapak tangan 3 macam.

\section{Menangkap bola gelinding}

Gambar 9 menangkap bola menggelinding

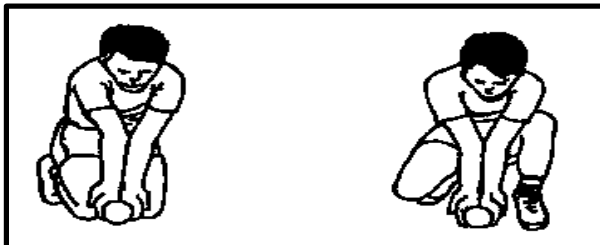

(sumber: ade mardiana, purwadi, dkk: 2008:

4.33)

\section{Memukul bola}

Cara memegang tongkat kayu pemukul yang baik dan mudah dilakukan oleh siswa adalah seperti sikap tangan pada saat berjabatan.

Beberapa macam memukul bola dalam permainan kasti:

\section{Pukulan depan/ fore hand}

Pukulan depan ini yang harus diutamakan karena mudah dilakukan, juga memberikan kemungkinan jarak pukulan akan lebih jauh.

Memukul bola mendatar dan bola melambung

Gambar 12 memukul bola mendatar dan melambung

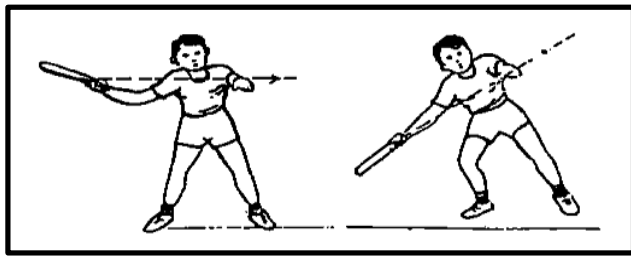

(sumber: ade mardiana, purwadi, dkk: 2008:

4.31)

Memukul bola merendah

Gambar 13 memukul bola rendah 


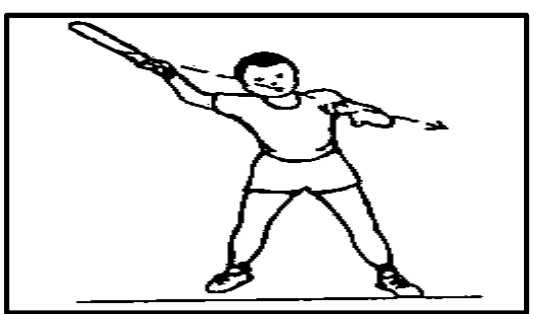

(sumber: ade mardiana, purwadi, dkk: 2008:

$$
\text { 4.31) }
$$

\section{Berlari}

Menurut Herman Subarjah (2007) Berlari dalam permainan kasti mempunyai peranan yang sangat penting bagi pemain kasti, hal ini untuk menghindari lemparan bola dari penjaga, ia harus terampil dalam lari menuju tiang pertolongan atau tiang hinggap dengan cepat. Disamping ia harus dapat berlari mengubah arah dengan tiba-tiba lari juga bisa dilakukan seperti: lari lurus, zig-zag, merunduk sambil berlari, melompat hal ini dilakukan supaya pelari tidak terkena lemparan bola dari lawan.

\section{Kecepatan}

Menurut Johansyah lubis (2013:92) Kecepatan adalah kemampuan untuk menempuh jarak dengan cepat. Kemampuan untuk bergerak cepat dalam garis lurus merupakan komponen yang terpisahkan dari sukses di berbagai olahraga. Garis lurus berlari dapat di bagi menjadi tiga tahap: akselerasi, pencapaian kecepatan maksimal, dan pemeliharaan kecepatan maksimal. Terdapat tiga jenis kecepatan yang sangat dibutuhkan dalam olahraga, yaitu :

1) Kecepatan reaksi adalah kualitas yang memungkinkan memulai sesuatu.

2) Jawaban kinetis secepat mungkin seyelah menerima suatu rangsangan.

3) Kecepatan bergerak adalah kualitas yang memungkinkan orang bergerak atau melaksanakan gerak-gerakan yang sama atau tidak sama secepat mungkin.

Kecepatan reaksi (reaction speed) juga dapat diartikan sebagai suatu kemampuan organisme alat untuk menjawab suatu rangsangan secepat mungkin dalam mencapai hasil sebaik-baiknya. sedangkan kecepatan bergerak (speed movement) adalah kemampuan organisme siswa untuk bergerak secepat mungkin dalam suatu gerakan yang tidak berputar. Kecepatan dinyatakan dengan $\mathrm{V}$ (velocity), jarak yang di tempuh dinyatakan dengan $\mathrm{D}$ (distance), dan waktu yang diperlukan untuk menempuh jarak tersebut dinyatakan dengan $\mathrm{T}$ (time).

\section{Kelincahan}

Menurut Johansyah lubis (2013:95) "Agility atau kelincahan adalah seperangkat keterampilan kompleks yang dilakukan oleh seseorang untuk merespons stimulus eksternal dengan perlambatan, perubahan arah, dan reacceleration". Kelincahan dipengaruhi oleh persepsi siswa/i dan pengambilan kemampuan mengambil keputusan untuk dengan cepat mengubah arah (young).

Pengaruh latihan kecepatan dan kelincahan terhadap lempar tangkap bola kastiMengkaji pengaruh latihan kecepatan dan kelincahan terhadap permainan bola kasti Menurut Johansyah lubis (2013:92) "kecepatan, kelincahan dan daya tahan kecepatan adalah kemampuan penting yang dapat mempengaruhi kinerja dalam berbagai olahraga".

Berdasarkan pendapat para ahli diatas dapat di paparkan pada kajian teori diatas dapat di simpulkan bahwa latihan kecepatan dan kelincahan dapat berpengaruh untuk meningkatkan lempar tangkap bola kasti. Latihan kecepatan dan kelincahan dapat meningkatkan pola permainan bola kasti, karena dengan latihan kecepatan dan kelincahan siswa dapat memahami pentingnya kecepatan dan kelincahan dalam permainan bola kasti.

\section{METODE}

Pre - test

Pretest dilakukan untuk mengetahui kecepatan dan kelincahan berlari sebelum diberikan perlakuan. Bertempat diSDN 19 Kota Bengkulu. Pada pukul 08:00 - selesai. Dalam tes ini diperlukan petugas pengukur 
waktu 2(dua) orang, pemberi aba-aba dan pencatat hasil.

\section{Post - test}

Post - test dilakukan untuk mengetahui pengaruh latihan kecepatan dan kellincahan terhadap permainan bola kasti kelas IV Sekolah Dasar Negeri 19 Kota Bengkulu. Bertempat di SDN 19 kota Bengkulu. Pada pukul 08:00 - selesai. Dalam tes ini diperlukan petugas pengukur waktu 2(dua) orang, pemberi aba-aba dan pencatat hasil.

\section{Instrumen Penelitian}

Instrumen penelitian sering dikenal dengan alat ukur. Menurut Sugiyono (2014: 102), instrumen penelitian adalah suatu alat yang digunakan mengukur fenomena alam maupun sosial yang diamati karena pada prinsipnya meneliti adalah melakukan pengukuran, maka dalam melakukan penelitian harus ada alat ukur yang baik. Jadi dapat ditarik kesimpulan bahwa instrumen adalah alat ukur yang digunakan untuk mengumpulkan data dalam sebuah penelitian.

\section{Uji validitas dan realibilitas instrumen Uji Validitas}

Validitas adalah apabila tes dapat tepat mengukur apa yang hendak diukur. Dalam penelitian ini, uji validitas digunakan untuk mengukur apakah pretest dan posttest valid atau tidak.

\section{Uji Realibilitas}

Menurut Arikunto (2010:100), suatu tes dapat dikatakan mempunyai taraf kepercayaan yang tinggi jika tes tersebut dapat memberikan hasil yang tetap atau sama. Berarti suatu tes yang reliabelakan mempunyai hasil yang sama walaupun telah dilakukan berulang - ulang. Dalam penelitian ini, uji realibilitas digunakan untuk mengujicobakan tes kepada siswa lain diluar populasi dan sampel. Sebuah tes dikatakan realibilitas jika rhitung > rtabel. Winarni, (2011: 177).
Dengan begitu norma yang di gunakan dalam uji normalitas dan realibilitas dalam latihan kecepatan dan kelincahan, yaitu: Norma Tes Kecepatan Tabel 1. norma kecepatan

\begin{tabular}{c|c|c}
\multicolumn{3}{|c}{ Laki - laki } \\
\hline No & Norma & Prestasi /Detik \\
\hline 1 & Baik Sekali & $3.58-3.91$ \\
\hline 2 & Baik & $3.92-4.34$ \\
\hline 3 & Sedang & $4.35-4.72$ \\
\hline 4 & Kurang & $4.73-5.11$ \\
\hline 5 & Kurang Sekali & $5.12-5.50$
\end{tabular}

Sumber: Evaluasi Pendidikan Jasmani dan Olahraga, Arsil (2010:95)

Perempuan

\begin{tabular}{c|c|c}
\hline No & Norma & Prestasi /Detik \\
\hline 1 & Baik Sekali & $4.06-4.50$ \\
\hline 2 & Baik & $4.51-4.96$ \\
\hline 3 & Sedang & $4.97-5.40$ \\
\hline 4 & Kurang & $5.41-5.86$ \\
\hline 5 & Kurang Sekali & $5.87-6.30$ \\
\hline
\end{tabular}

Sumber: Evaluasi Pendidikan Jasmani dan Olahraga, Arsil (2010:95)

Norma kelincahan

Tabel 2. norma kelincahan

\begin{tabular}{c|c|c}
\multicolumn{3}{c}{ Laki - laki } \\
\hline No & Norma & Prestasi /Detik \\
\hline 1 & Baik Sekali & Keatas 12.10 \\
\hline 2 & Baik & $12.11-13.53$ \\
\hline 3 & Sedang & $13.54-14.96$ \\
\hline 4 & Kurang & $14.97-16.39$ \\
\hline 5 & Kurang Sekali & $16.40-$ kebawah \\
\hline
\end{tabular}

Sumber: Evaluasi Pendidikan Jasmani dan Olahraga, Arsil (2010:98)

Perempuan

\begin{tabular}{c|c|c}
\hline No & Norma & Prestasi /Detik \\
\hline 1 & Baik Sekali & Ke atas 12.42 \\
\hline 2 & Baik & $12.43-14.09$ \\
\hline 3 & Sedang & $14.10-15.74$ \\
\hline 4 & Kurang & $15.75-17.39$ \\
\hline 5 & Kurang Sekali & $17.40-$ ke bawah \\
\hline
\end{tabular}

Sumber: Evaluasi Pendidikan Jasmani dan Olahraga, Arsil (2010:98) 
Norma penilaian lempar tangkap bola kasti Tabel 3. norma lempar tangkap

\begin{tabular}{c|c|c}
\hline Kategori & Putra & Putri \\
\hline Sangat Baik & $\geq 40$ & $\geq 35$ \\
\hline Baik & $35-40$ & $30-35$ \\
\hline Sedang & $25-34$ & $20-29$ \\
\hline Kurang & $15-24$ & $10-19$ \\
\hline Sangat Kurang & $\leq 15$ & $\leq 10$ \\
\hline
\end{tabular}

Sumber: seleksi bersama masuk perguruan tinggi negeri (SBMPTN), (2015)

\section{Teknik Analisis Data}

Analisis data ini dilakukan dengan membandingkan kemampuan pre-test dan post-test eksperimen pada siswa kelas IV Kota Bengkulu yang telah ditentukan. Analisis ini menggunakan uji satu sampel untuk rata-rata (one sample $t$ test). Dengan uji tersebut akan diketahui apakah ada pengaruh antara nilai rata-rata pre-test dan post-test kelas eksperimen.

\section{Analisis Data Tahap Awal}

Sebelum dilakukan uji one sample $\mathrm{t}$ test, terlebih dahulu diuji normalitas untuk mengetahui apakah siswa kelas IV eksperimen berdistribusi normal atau tidak. Jika kelas IV tersebut berdistribusi normal, maka statistik yang digunakan adalah statistik parameter.

\section{Uji Normalitas}

Uji normalitas digunakan untuk mengolah data nilai pre-test dalam menentukan apakah siswa kelas IV yang telah diuji, berdistribusi normal atau tidak. Rumus pengujian ini dikenal dengan Chi Kuadrat.

\section{Uji Homogenitas}

Apabila diketahui data berdistribusi normal, maka langkah selanjutnya adalah melakukan uji homogenitas varian. Hipotesis statistik yang digunakan adalah $\mathrm{Ha}$ dapat diterima apabila $\mu_{1}{ }^{2}$ lebih besar dari $\mu_{2}{ }^{2}$ sedangkan Ho dapat diterima apabila $\mu_{1}^{2}$ sama dengan $\mu_{2}^{2}$.

$\mathrm{Ha}$ adalah hipotesis yang menyatakan skor kedua kelas IV memiliki varian yang tidak sama, dan Ho adalah hipotesis yang menyatakan skor kedua kelas IV memiliki varian yang sama.Uji Bartlett (digunakan untuk menguji homogenitas varians lebih dari dua kelompok data.

\section{Analisis Data Tahap Akhir}

Metode untuk menganalisis data nilai akhir setelah diberi perlakuan adalah sebagai berikut:

\section{Uji t}

Uji perbedaan dua rata-rata digunakan untuk mengetahui pengaruh hasil pre - test sebelum diberikan perlakuan (treatment) dan hasil post - test sesudah diberi perlakuan (treatment). Untuk mengetahui perbedaan dua rata-rata ini menggunakan uji satu pihak (uji t) yaitu uji pihak kiri.

\section{HASIL DAN PEMBAHASAN Hasil Penelitian}

Dari daftar distribusi t diperoleh t 1,980 dengan $\mathrm{dk}=118$ adalah 2,00, berarti kriteria pengujinya adalah terima $\mathrm{Ha}$ jika $t_{\text {hitung }}$ terletak antara $-2,00$ dan 2,00, sedangkan $t_{\text {hitung }}$ diperoleh sebesar 0,61 berarti Ha diterima. Kesimpulan terdapat pengaruh latihan kecepatan dan kelincahan terhadap lempar tangkap bola kasti pada tingkat signifikan $5 \%$.

\section{Pembahasan}

Dari hasil perlakuan yang telah diberikan selama 16 kali pertemuan maka didapat peningkatan lempartangkap bola kasti pada siswa, dengan cara tes akhir di kurangi tes awal.

Berdasarkan hasil penelitian dan analisis statistik yang telah kemukakan di atas, selanjutnya pada bagian ini akan dikaitkan pembahasan tentang pengaruh latihan kecepatan dan kelincahan terhadap lempar tangkap bola kasti untuk siswa/i SD negeri 19 Kota Bengkulu.

Proses latihan kecepatan dan kelincahan terhadap lempar tangkap bola kasti, dengan cara siswa test kecepatan berlari 30meter dengan waktu tercepat dan test kelincahan berlari bolak balik dengan 
waktu 10 menit selama 4 akali bolak balik, setelah itu kemudian siswa melatih lempar dan menangkap ke dinding sasaran sebanyak - banyaknya selama 30 detik. Menurut Widiastuti " kecepatan adalah kemampuan berpindah dari satu tempat ke tempat lain dalam waktu sesingkat - singkatnya. Kecepatan bersifat lokomotor dan gerakannya bersifat siklik (satu jenis gerak yang dilakukan berulang - ulang seperti lari dan sebagainya) atau kecepatan gerakbeagian tubuh seperti melakukan pukulan. Kecepatan penting tidak saja beagi anak - anak terutama saat mereka bermain di sekolah maupun di rumah juga bagi mereka yag sudah dewasa untuk dapat tetap menjaga stabilitasnya".

Test kelincahan menurut Widiastuti "kelincahan adalah kemampuan untuk mengubah arah atau posisi tubuh dengan cepat yang dilakukan bersama - sama dengan gerakan lainnya. Jad kelincahan harus menempati prioritas utama dalam melatih kesegaran jasmani setiap anak".

Latihan kecepatan dan kelincahan terhadap lempar tangkap bola kasti, otototot lengan atas/lengan bawah sangat mempegaruhi untuk melakukan lemparan bola kasti dikarenakan power dari otot-otot sangat mempengaruh untuk kecepatan melempar dan menangkap bola kasti tersebut. Selain itu juga otot tungkai juga dapat mempengaruhi melempar dan menangkap bola kasti karena otot tungkai dapat membatu proses lempar tangkap agar di lakukan dengan sempurna atau yang di harapkan. Kecepatan juga merupakan salah satu aspek kemampuan yang di perlukan dalam cabang olahraga tertentu, kecepatan adalah kemampuan untuk melakukan gerakan yang sejenis secara berturut-turut dalam waktu yang sesingkat-singkatnya, atau kemampuan untuk menempuh suatu jarak dalam waktu yang sesingkat - singkatnya. Maka terdapat hubungan yang signifikan latihan kecepatan dan kelincahan terhadap peningkatan lempar tangkap bola kasti. Hasil penelitian ini bisa dilihat persamaanny di kajian penelitian relevan halaman 22 .

Dengan demikian latihan kecepatan dan kelincahan sangat signifikan untuk meningkatkan lempar tangkap untuk siswa/i kelas IV Sekolah Dasar negeri 19 Kota Bengkulu dan juga bisa menunjang kreatifitas anak atau siswa/i dalam gerak lokomotor, non lokomotor dan psikomotor di dalam sebuah permainan bola kasti.

\section{PENUTUP \\ Simpulan}

Berdasarkan uraian analisis data dan pembahasan maka dapat dikemukakan beberapa kesimpulan sebagai berikut :

Latihan kecepatan dan kelincahan mempunyai pengaruh yang signifikan. Hal ini dapat dilihat dari uji t yang dilakukan, dimana $t_{\text {observasi }}$ lebih kecil dari $t_{\text {tabel }}$, nilai t yang diperoleh dari tes awal dan tes akhir sebesar 0,617 dan $t$ tabel 1,980.

Latihan kecepatan dan kelincahan mempunyai pengaruh terhadap lempar tangkap bola kasti untuk siswa/i SD negeri 19 kota bengkulu. Hal ini dapat dilihat dari peningkatan harga mean tes tes akhir, dimana peningkatan harga mean tes awal dan tes akhir kecepatan dan kelincahan adalah 0,617.

\section{Saran}

Berdasarkan kesimpulan hasil penelitian diatas maka disarankan :

Bagi siswa/i SD negeri 19 kota bengkulu bisa memahami tentang prioritasnya dalam mengikuti latihan agar kondisi fisiknya dan kemampuannya terus bisa meningkat.

Bagi para guru PJOK agar menggunakan metode latihan yang tidak monoton cobalah menggunakan metode variasi atau modifikasi yang dimana dengan cara belajar tersebut bisa meningkatkan prestasi siswa dan juga agar setiap belajar siswa tidak merasa bosan.

Bagi peneliti untuk membantu guru PJOK dalam melakukan latihan kondisi siswa sebelum melakukan pelajaran PJOK, kalau kondisi siswanya segar bugar, fisik, mental 
dan tekniknya bagus pasti siswa mengikuti mata kuliah PJOK dengan semangat dan sehat.

\section{DAFTAR PUSTAKA}

Arsil, (2010). Evaluasi Pendidikan Jasmani dan olahraga. Padang : Wineka Media

Dokumen instruksi kerja, prosedur pelaksanaan, dan instrumen penilaian ujian keterampilan olahraga dan seni. Tes SBMPTN (2015)

Lubis J, (2013). Panduan praktis penyusunan program latihan. Jakarta : Rajawali Pers

Mardiana Ade; purwadi; dan Satya,W.I. (2008). Pendidikan Jasmani dan Olahraga. Jakarta : Universitas Terbuka

Sukrisno; dkk (2009). Pendidikan Jasmani, Olahraga, dan Kesehatan untuk SD/MI Kelas IV. Jakarta: Penerbit Erlangga

Sugiyono, (2014). Metode penelitian kuantitatif, kualitatif dan R\&D. Bandung: Penerbit Alfabeta

Utami, H. P. (2008). Permainan Kasti dan Sejenisnya. Jakarta: Penerbit Ganeca Exact

Wiarto Giri, (2015). Inovasi pembelajaran dalam Pendidikan Jasmani. Yogyakarta: Laksitas

Widiastuti, (2011). Test dan pengukuran olahraga. Jakarta: PT Bumi Timur Jaya 